\title{
MOTIVOS QUE LEVAM ADOLESCENTES A PRATICAREM FUTSAL
}

Paulo Ricardo Martins Nuñez

Helen Fabianny Souza de Lara Picada

Sandro Torales Schulz

Carlos Alexandre Habitante

Junior Vagner Pereira da Silva

\section{Resumo}

Nos últimos anos, os estudos relacionados à psicologia esportiva têm ganhado considerável espaço no meio acadêmico brasileiro, principalmente naqueles relacionados aos aspectos motivacionais. Conhecer os motivos que levam jovens a praticarem determinada modalidade esportiva é de grande relevância para professores e treinadores, pois a motivação é pré-requisito para a permanência de um indivíduo em um programa esportivo. Diante do exposto, este estudo teve por objetivo avaliar os motivos que levam adolescentes a praticarem futsal. A amostra foi composta por 100 alunos/atletas, de 13 a 16 anos, do sexo masculino, inscritos em sete equipes de escolas particulares de Campo Grande - MS. Como instrumento, utilizou-se o Inventário de Motivação para a prática Desportiva de Gaya e Cardoso (1998). Os dados mostram que praticar futsal para o rendimento esportivo $(\mathrm{M}=3,92)$ configura-se como a principal motivação de adesão ao esporte, seguido pela saúde $(M=3,79)$ e pela amizade/lazer $(M=3,34)$. A maior motivação dos jovens em praticarem futsal para o rendimento esportivo pode ser em decorrência dos adolescentes terem um grande ímpeto para atividades competitivas, uma vez que, por intermédio delas, suas potencialidades são evidenciadas.

\section{Palavras-Chave}

Rendimento esportivo; Saúde; Lazer.

\section{THE REASONS MAKE ADOLESCENTS PRACTICE "FUTSAL"(five-a-side soccer)}

Paulo Ricardo Martins Nuñez

Helen Fabianny Souza de Lara Picada

Sandro Torales Schulz

Carlos Alexandre Habitante

Junior Vagner Pereira da Silva

\begin{abstract}
During the last years, the studies related to sports psychology have been getting a considerable place on the brazilian academic circles, mainly on those related to motivational aspects. It is very important to teachers and coachers to know the reasons that make adolescents practice a certain sport, as motivation is a pre-requisite to the permanence of a person on a sports program. So, the aim of this study was to investigate the reasons that make adolescents practice "futsal". The sample was composed by 100 male students/athletes, at age from 13 to 16 years-old, members of seven "futsal" groups of private schools in Campo Grande - MS. The tool used was the "Inventário de Motivação para a prática Desportiva" de Gaya e Cardoso (1998). And the data showed that the practice the "futsal" related to the sport
\end{abstract}


performance $(\mathrm{M}=3,92)$ is the main motivation to the entrance to the sport, followed by the health $(M=3,79)$ and friend/leisure $(M=3,34)$. The strongest motivational aspect of the adolescents in practicing "futsal" was the sports performance which could have occurred as a consequence to their strong desire to practice competitive activities, as, by these competitions, their potentialities are evidenced.

\section{Key-Words}

Sports performance; Health; Leisure. 


\section{INTRODUÇÃO}

$\mathrm{Na}$ relação ensino/aprendizagem, em qualquer ambiente, a motivação se constitui num dos elementos centrais para o alcance do objetivo pretendido. Quando se trata da aprendizagem de habilidades motoras, Krug (2002) expõe que a motivação é fundamental.

Para Rodrigues (1997), um dos principais fatores que interferem no comportamento de uma pessoa é, indubitavelmente, a motivação; uma vez que esta influencia, com muita propriedade, em todos os tipos de comportamentos, permitindo um maior envolvimento ou uma simples participação em atividades relacionadas à aprendizagem, ao desempenho e à atenção.

Segundo Pfromm Neto (1987), o indivíduo motivado encontra-se disposto a despender esforços para alcançar seus objetivos. Desta forma, a motivação aparece como uma tendência interna, que leva o indivíduo a agir em direção a determinado objetivo. O comportamento é estimulado para algum tipo de mudança, implicando na aquisição de aprendizagens de tal forma que o sujeito consiga reduzir a ansiedade e aumentar seu sentimento de prazer. Ao alcançar desempenhos bem sucedidos, há um aumento do desejo específico de resultados, aumentando a satisfação e, conseqüentemente, a motivação do indivíduo.

Becker Júnior (2000) considera a motivação fator muito importante na busca de qualquer objetivo pelo ser humano, uma vez que os treinadores, tanto nos treinamentos quanto nas competições, reconhecem constantemente esse fato como sendo o principal. Assim, a motivação acaba se constituindo elemento básico para o atleta seguir as orientações do treinador e praticar diariamente as sessões de treinamento.

Buscando diferenciar os comportamentos motivacionais, Samulski (1990) classifica a motivação em aspectos intrínsecos e extrínsecos. Os aspectos intrínsecos referem-se a algo interno e inseparável, que vem de dentro da pessoa; os extrínsecos estão relacionados aos fatores externos (ambientais). A razão pela qual se faz algo é apenas um meio para se alcançar um outro objetivo maior, quando a ação em si só não satisfaz.

De acordo com Cratty (1983), indivíduos motivados intrinsecamente têm maior probabilidade de serem mais persistentes e de apresentarem níveis de desempenho mais altos do que os motivados extrinsecamente. Os agentes socializantes, segundo Samulski (1995), também influenciam no interesse 
dos jovens pela prática desportiva, sendo esses percebidos como estímulos externos. Observa-se, então, que o atleta competitivo valoriza mais o esforço externo, enquanto o atleta cooperativo, o interno.

Segundo a Teoria Cognitiva da Motivação, existem dois tipos de pessoas: aquelas que são motivadas pela esperança de êxito, atribuindo os seus resultados à própria capacidade; e as que são motivadas pelo medo do fracasso, que atribuem-nos à dificuldade da tarefa ou ao acaso. Isto é, ainda que duas pessoas treinem muito para uma determinada competição, cada uma delas pode estar empenhando-se por êxitos diferentes (SAMULSKI, 1990).

Ainda para Samulski (1990), o objetivo do ensino e treinamento deve desenvolver no aluno/atleta a capacidade de autocontrole, auto-motivação (motivação intrínseca) e a capacidade de assumir responsabilidade em situações de fracasso.

Segundo Webster apud Marques (2003), a atitude do técnico/professor frente a sua equipe antes do jogo pode ser encorajadora - apesar da ansiedade gerada pela competição e vontade de perseguir a vitória -, ou pode ser frustradora, criando um nível tão alto de ansiedade que interfere no desempenho dos jogadores, bloqueando as atividades positivas, acarretando-lhes uma derrota.

Nesse sentido, o conhecimento dos motivos que levam adolescentes a praticarem uma atividade motora é um aspecto de bastante interesse no desenvolvimento humano e de grande importância para professores de educação física e técnicos, pois proporciona subsídios necessários para a estimulação de seus programas e aulas específicas, ou seja, voltados para o interesse do praticante, que facilitem a escolha das atividades, o ritmo da aula, o comportamento relacional e a maneira de motivar para a prática alegre e prazerosa. Assim, este estudo teve por objetivo avaliar quais motivos levam os adolescentes a praticarem a modalidade futsal como esporte.

\section{PROCEDIMENTOS METODOLÓGICOS}

A população do estudo foram atletas de futsal, com idade entre 13 a 16 anos, do sexo masculino, integrantes de sete equipes de escolas da Rede de Ensino Particular de Campo Grande - MS. A amostra foi composta por 100 atletas, selecionados de forma não-probabilística, conforme indicações de Thomas e Nelson (2002). 
Como instrumento utilizou-se o Inventário de Motivação para a Prática Desportiva, criado por Gaya e Cardoso (1998). Esse instrumento é composto por 19 questões fechadas, subdivididas em três categorias rendimento desportivo, saúde e amizade/lazer. As categorias são compostas pelas seguintes questões:

a) Rendimento Desportivo - vencer (q1), para ser o melhor no esporte (q4); para competir (q8); para ser um atleta (q9); para desenvolver habilidades (q15); para aprender novos esportes (q16) e para ser jogador quando crescer (q17);

b) Saúde - para exercitar-se (q2); para manter a saúde (q5); para desenvolver a musculatura (q10); para ter um bom aspecto (q11); para manter o corpo em forma (q14) e para emagrecer (q18);

c) amizade/lazer - para brincar (q3); porque eu gosto (q6); para encontrar os amigos (q7); para divertir-me (q12); para fazer novos amigos (q13) e para não ficar em casa (q19).

Cada questão possui cinco possibilidades de respostas (nada importante, pouco importante, importante, muito importante e muitíssimo importante).

Para análise estatística, as respostas qualitativas foram codificadas quantitativamente - nada importante (1), pouco importante

(2), importante

(3), muito importante

(4) e muitíssimo importante

(5), tabulados em planilha do Microsoft Excel e transferidos para análise no programa estatístico SPSS 13.0 for Windows. No tratamento dos dados recorreu-se à análise de freqüência (valor absoluto) e de tendência central (média).

\section{RESULTADOS E DISCUSSÃO}

Analisando os resultados por categoria, conforme pode ser observado na tabela 1, constatou-se que os principais motivos que levam os adolescentes avaliados à prática do futsal é desenvolver habilidades, ser um atleta e vencer. 


\section{Tabela 1- Freqüência e média do grau de motivação dos atletas na prática do futsal na categoria rendimento desportivo}

\begin{tabular}{lcccccc}
\hline \multicolumn{1}{c}{ Rendimento desportivo } & \multicolumn{9}{c}{ Grau de importância } & Média \\
& 1 & 2 & 3 & 4 & 5 & \\
Para vencer & 0 & 4 & 26 & 21 & 49 & 4,15 \\
\hline Para ser o melhor no esporte & 6 & 10 & 24 & 19 & 41 & 3,79 \\
Para competir & 4 & 8 & 27 & 26 & 35 & 3,8 \\
\hline Para ser um atleta & 2 & 2 & 22 & 24 & 50 & 4,18 \\
Para desenvolver habilidades & 0 & 10 & 14 & 36 & 49 & 4,51 \\
\hline Para aprender novos esportes & 7 & 12 & 41 & 21 & 19 & 3,33 \\
Para ser jogador quando crescer & 12 & 11 & 16 & 14 & 47 & 3,73 \\
\hline
\end{tabular}

Legenda: nada importante (1), pouco importante (2), importante (3), muito importante (4) e muitíssimo importante (5)

Dados similares foram encontrados nos estudos de Wankel e Kreisel (1985). Na ocasião, os autores constataram que as razões intrínsecas, tais como melhorar a habilidade e se apresentar bem no esporte, eram os principais motivos para a freqüência em uma atividade esportiva.

Myotin (1995) relata que a prática esportiva relacionada à melhoria das habilidades é motivo de grande importância para os jovens, principalmente para os do sexo masculino que são bastante motivados por questões relacionadas à realização pessoal.

Hahn (1988) também constatou que vencer e competir eram os principais motivos a levarem crianças à pratica de esportes. Segundo o autor, isso ocorre devido a um constante desejo de comparação entre os jovens, fazendo com que a competição seja fator altamente relevante nessa faixa etária. Segundo Krug (2002), o desejo de experimentar novos desafios para colocar em evidência suas potencialidades é uma das principais características dos adolescentes.

Em relação à prática esportiva relacionada à saúde, observou-se que a manutenção da saúde e do corpo em forma são os principais motivos a levarem os adolescentes investigados à pratica do futsal. 
Tabela 2- Freqüência e média do grau de motivação dos atletas na prática do futsal na categoria saúde

\begin{tabular}{lcccccc}
\hline \multicolumn{1}{c}{ Saúde } & \multicolumn{9}{c}{ Grau de importância } & Média \\
& 1 & 2 & 3 & 4 & 5 & \\
\hline Para exercitar-se & 1 & 3 & 32 & 26 & 38 & 3,97 \\
Para manter a saúde & 0 & 0 & 14 & 21 & 65 & 4,51 \\
\hline Para desenvolver a musculatura & 1 & 9 & 19 & 34 & 37 & 3,97 \\
Para ter bom aspecto & 1 & 10 & 36 & 25 & 28 & 3,69 \\
\hline Para manter o corpo em forma & 1 & 6 & 26 & 22 & 45 & 4,04 \\
Para emagrecer & 30 & 25 & 16 & 15 & 14 & 2,58 \\
\hline
\end{tabular}

Legenda: nada importante (1), pouco importante (2), importante (3), muito importante (4) e muitíssimo importante (5)

Segundo Scalon, Becker Junior e Brauner (1999), geralmente os jovens se preocupam com a saúde, aderindo a um hábito saudável, além de aprender e aprimorar novas técnicas e habilidades esportivas.

A maior motivação para manter a saúde, nessa categoria, pode estar sendo influenciada por fatores extrínsecos como a família, pois, de acordo com Tani (2001), na atualidade existe grande preocupação por parte dos pais com a qualidade de vida e saúde de seus filhos, sendo o esporte muitas vezes utilizado como meio de prevenção de doenças associadas ao sedentarismo.

A presença da manutenção do corpo em forma como um dos principais motivos para a prática do futsal, conforme exposto por Machado, Piccoli e Scalon (2005), pode estar relacionado à importância que a estética corporal tem ocupado na Sociedade Contemporânea, pois, muitas vezes, ela acaba sendo utilizada como pré-requisito para aceitação ou rejeição social.

A exemplo do constatado por Paim (2004) e Paim e Pereira (2005), na categoria amizade/lazer, praticar futsal porque gosta, configurou-se como o principal motivo. 
Tabela 3- Freqüência e média do grau de motivação dos atletas na prática do futsal na categoria amizade/lazer

\begin{tabular}{lcccccc}
\hline \multicolumn{1}{c}{ Lazer/Amizade } & \multicolumn{7}{c}{ Grau de importância } & Média \\
& 1 & 2 & 3 & 4 & 5 & \\
\hline Para brincar & 14 & 30 & 31 & 5 & 20 & 2,87 \\
Porque eu gosto & 0 & 4 & 17 & 26 & 53 & 4,28 \\
\hline Para encontrar amigos & 6 & 22 & 31 & 18 & 23 & 3,33 \\
Para me divertir & 4 & 14 & 29 & 30 & 23 & 3,54 \\
\hline Para fazer novos amigos & 7 & 16 & 37 & 22 & 18 & 3,28 \\
Para não ficar em casa & 23 & 25 & 23 & 11 & 18 & 2,76 \\
\hline
\end{tabular}

Legenda: nada importante (1), pouco importante (2), importante (3), muito importante (4) e muitíssimo importante (5)

Segundo Lawther (1973), gostar de praticar é de suma importância para a permanência de um indivíduo em uma modalidade esportiva, pois o valor educacional, o valor recreativo e o valor de saúde mental existente nos esportes, tendem a diminuir quando a atividade não é divertida.

Além de praticar o futsal porque gosta, a maioria dos adolescentes também afirmou aderir a esse esporte pelo divertimento que o mesmo provoca. De acordo com Gould (1987), o divertimento e a excitação no esporte são extremamente importantes para que os jovens permaneçam ativos na vida adulta, principalmente se esses esportes tiverem sido fontes de prazer e de alegria na infância.

Embora em muitos casos crianças pratiquem esportes motivados em fazer amigos e/ou reforçar laços de amizade, conforme exposto por Santiago e Messina (2003), esses motivos foram os que apresentaram os menores percentuais em nosso estudo. Isso pode ter acontecido em decorrência da faixa etária da população avaliada (adolescentes); segundo os mesmos autores, enquanto as crianças estão mais interessadas em fazer amigos e fortalecer laços de amizades, os jovens praticam esporte para obterem maior desempenho e habilidades.

No geral, a exemplo do constatado nos estudos de Paim (2001), Paim (2003) e Paim (2004), a maioria dos adolescentes praticavam o futsal motivados pelo rendimento esportivo. 
Tabela 4- Média geral, por categoria, do grau de motivação dos atletas na prática do futsal

\begin{tabular}{lc}
\hline Rendimento desportivo & Média \\
Rendimento esportivo & 3,92 \\
\hline Saúde & 3,79 \\
Amizade/Lazer & 3,34 \\
\hline
\end{tabular}

O maior envolvimento dos adolescentes com a prática do futsal pelo rendimento pode estar relacionado à questões intrínsecas, pois, de acordo com Lawther (1973), experimentar novos desafios para evidenciar suas potencialidades são ações características dos adolescentes.

No entanto, há de se considerar que a motivação é um processo relacionado à integração de fatores intrínsecos e extrínsecos, tendo os extrínsecos grande influência nas decisões e metas a serem seguidas pelo atleta (SAMULSKI, 1995). Assim, a maior motivação dos jovens pelo rendimento esportivo também pode ser decorrente da popularização desse esporte e de seus atletas, uma vez que, com freqüência, suas competições são transmitidas pela mídia tanto em nível de Brasil (Copa do Brasil) quanto de Mato Grosso do Sul (Copa Morena, Copa Canarinho e Copa da Juventude).

Embora a maioria dos estudos com jovens tenha apontado o rendimento como a principal motivação à prática esportiva, estudos desenvolvidos por Paim (2004) e Machado, Piccoli e Scalon (2005) constataram que a busca pela melhoria na saúde configuraram-se como o principal motivo da prática de esportes. Para Paim (2001) isso tem ocorrido pela relação existente entre esporte e saúde e por sua divulgação como fator de prevenção de doenças relacionadas ao sedentarismo.

\section{CONCLUSÃO}

Através do presente estudo objetivou-se identificar os fatores motivacionais que levam atletas adolescentes de uma escola particular de Campo Grande - MS a praticarem o futsal. A exemplo do relatado pela literatura, os resultados apontam o rendimento esportivo, seguido pela saúde, como principais motivos.

Há indícios de que o maior envolvimento dos jovens com o esporte pelo rendimento seja decorrente das características intrínsecas dessa faixa etária (competitividade/auto-afirmação), todavia, não se podem descartar as possíveis influências exercidas por fatores extrínsecos, tal como a família, treinador, amigos e a mídia. 


\section{REFERÊNCIAS}

BECKER JR., B. Manual de psicologia do esporte e exercício. Porto Alegre: Nova Prata, 2000.

CRATTY, B. J. Psicologia do esporte. Rio de Janeiro: Prentice Hall, 1983.

GAYA, A.; CARDOSO, M. Os fatores motivacionais para a prática desportiva e suas relações com o sexo, idade e níveis de desempenho desportivo. Revista Perfil, ano 2, n. 2, 1998.

GOULD, D. Psychosocial development anda children's sport. In: THOMAS, J. R. (ed.) Motor development during childhood and adolescence. Minneapolis: Burgess, 1987.

HAHN, E. Entrenamiento con niños. Teoría, práctica, problemas específicos. Barcelona: Martines Roca, 1988.

KRUG, H. N. Educação física escolar: temas polêmicos. Cadernos de ensino, pesquisa e extensão do Centro da UFSM, n. 53, p. 1-49, 2002.

LAWTHER, L. Psicologia desportiva. Rio de Janeiro: Fórum, 1973.

MACHADO, C. S.; PICCOLI, J. C. J.; SCALON, R. M. Fatores motivacionais que influem na aderência de adolescentes os programas de iniciação desportiva das escolas da Universidade Luterana do Brasil. Revista Digital, v. 10, n. 89, 2005. Disponível em: <http://www.efdeportes.com>.

MARQUES, G. M. Psicologia do Esporte: Aspectos que os atletas acreditam. Canoas: Editora Ulbra, 2003.

MESSINA, U. J. O.; SANTIAGO, J. S. Motivação no esporte: uma discussão sobre razões de busca da prática esportiva entre crianças e adolescentes. In: SEMANA DA EDUCAÇÃO FÍSICA DA UNIVERSIDADE ESTADUAL DE MARINGÁ, 16², 2003, Maringá. Anais... Maringá, 2003. v. 1.

MYOTIN, E. A. A participação da adolescente brasileira em esportes e atividades físicas como forma de lazer: fatores psicológicos e socioculturais. In: ROMERO, E. (Org.). Corpo, Mulher e sociedade. Campinas: Papirus, 1995, p. 177-197.

PAIM, M. C. C. Motivos que levam adolescentes a praticar o futebol. Revista Digital, Año 7, n. 43, 2001. Disponível em: <http://www.efdeportes.com>.

. Motivos que levam adolescentes a praticar o futebol. Revista Digital, Año 7, n. 43, 2001 Disponível em: $<$ http://www.efdeportes.com>.

PAIM, M. C. C. Fatores motivacionais e desempenho no futebol. Revista Virtual EFArtigos. v. 2, n. 7, 2004. 
PAIM, M. C. C. ; PEREIRA, É. F. Fatores motivacionais em adolescentes para prática de jazz. Revista da Educação Física/UEM, v. 16, n. 1, p. 59-66, 2005.

PFROMM NETO, S. A psicologia da aprendizagem e do ensino. São Paulo: Edu-Edusp, 1987.

RODRIGUES, P. A motivação e performance. 1991. Monografia (Graduação) - Instituto de Biociências, Universidade Estadual Paulista, Rio Claro, 1991.

SAMULSKI, D. M. Psicologia do esporte. Belo Horizonte: Ed. UFMG, 1990.

. Psicologia do esporte: teoria e aplicação prática. Belo Horizonte: Imprensa Universitária UFMG, 1995.

SCALON, R. M.; BECKER JR. B.; BRAUNER, M. R. G. Fatores motivacionais que influencia na aderência dos programas de iniciação desportiva pela criança. Revista Perfil, ano 3, n. 3, p. 51-61, 1999.

TANI G. A criança no esporte: implicações da iniciação esportiva precoce. In: KREBS, R. J. Desenvolvimento infantil em contexto. Florianópolis: UDESC, 2001. p. 101-113.

THOMAS, J. R.; NELSON, J. K. Métodos de pesquisa em atividade fisica. Porto Alegre: Artmed, 2002. WANKEL, L. M.; KREISEL, P. S. J. Factores underlying enjorment of yunth sports: Sport and age group comparisons. Jounarl of Sport Psychology. Champaing, v. 7, n. 1, p. 51-64, 1985. 
Paulo Ricardo Martins Nuñez

Universidade para o Desenvolvimento do Estado e da Região do Pantanal

Helen Fabianny Souza de Lara Picada

Universidade para o Desenvolvimento do Estado e da Região do Pantanal

Sandro Torales Schulz

Universidade para o Desenvolvimento do Estado e da Região do Pantanal

\section{Carlos Alexandre Habitante}

Universidade para o Desenvolvimento do Estado e da Região do Pantanal

\section{Junior Vagner Pereira da Silva}

Universidade para o Desenvolvimento do Estado e da Região do Pantanal

Referência do artigo:

ABNT

NUÑEZ, P. R. M. et. al. Motivos que levam adolescentes a praticarem futsal. Conexões, v. 6, n. 1, p. 6778.

\section{APA}

Nuñes, P. R. M., Picada, H. F. S. L., Schulz, S. T., Habitante, C. A., \& Silva, J. V. P. (2008). Motivos que levam adolescentes a praticarem futsal. Conexões, 6(1), 67-78.

\section{VANCOUVER}

Nuñes PRM, Picada HFSL, Schulz ST, Habitante CA, Silva JVP. Motivos que levam adolescentes a praticarem futsal. Conexões, 2008, 6(1): 67-78. 